\title{
CBDD Terminology
}

National Cancer Institute

\section{Source}

National Cancer Institute. CBDD Terminology. NCI Thesaurus. Code C157225.

The Chemical Biology and Drug Development (CBDD) Terminology is a set of terms used in design, development, and description of drug substances, mainly but not exclusively pertaining to the chemistry (including chemical reactions) of small molecules and polymers. The terminology is intended to support the chemoinformatics community's effort to develop conceptual models for describing modern drug design such as performed by the NCl Computer-Aided Drug Design (CADD) Group (part of the $\mathrm{NCl}$ Chemical Biology Laboratory) and collaborators at NIH, academia, and other government agencies. 